\title{
Taller sobre el uso de los tipos de trabajo práctico como herramienta fundamental para enseñar ciencias
}

\author{
Workshop about the use of different practical work types as fundamental tool to teach \\ sciences
}

Manuel Fredy Molina C., José G. Carriazo B. y Diana Farias C.

Departamento de Química, Universidad Nacional de Colombia. Grupo de investigación en enseñanza de la química. mfmolinac@unal.edu.co , jcariazog@unal.edu.co , dmfariasc@unal.edu.co

\section{Resumen}

Aquí presentamos la dasificación y características de cuatro tipos de trabajo práctico (experiencias, experimentos ilustrativos, ejercicios prácticos e investigaciones), con ejemplos apropiados que se pueden desarrollar en el aula o laboratorio. Para cada uno indicamos sus intenciones y forma de desarrollo en una dase de ciencias, particularmente en la dase de química. Con esto buscamos motivar a los docentes de ciencias a utilizar las actividades prácticas como estrategia exitosa, bien fundamentada, en los procesos de enseñanza, y damos ejemplos para que cada uno se convierta en un profesor que involucre activa y positivamente a sus estudiantes en las actividades de enseñanza-aprendizaje.

\section{Palabras clave}

Trabajo práctico, enseñanza de las ciencias, química, laboratorio.

\section{Abstract}

We present here the characteristics and classification of four types of practical work (experiences, illustrative experiments, practical exercises and inquiry-based works), by appropriate examples which can be developed into the dassroom or in the laboratory. For each one we indicate its intentions and form to carry out it through a science class, particularly in a chemistry class. We seek to motivate the sciences teachers to use the practical activities as a successful strategy, well founded, on the teaching processes, giving several examples to each educator can be converted to a teacher who involve active and positively to their students into the different teaching-learning activities.

\section{Keywords}

Practical work, sciences teaching, chemistry, laboratory.

\section{Introducción}

La enseñanza de las ciencias en Colombia parece que no atraviesa por buen momento, conclusión que se puede sacar de los resultados en la evaluación intemacional PISA 2006, donde obtuvimos un puntaje bajo (388 puntos, con respecto al de 563 de Finlandia y el mínimo de 322 de Kirguistán, frente a un promedio general de 491 puntos para 57 países) (Caamaño, 2008). Sin embargo, más que desalentamos por los resultados estamos dispuestos a pensar en opciones para mejorar lo que se realiza en el aula. Dirigiremos nuestra mirada particularmente a la química, pero las mismas sugerencias pueden pasarse a la física, la biología y a las ciencias naturales en general. 
Para tal fin, nos centraremos en el uso del trabajo práctico en las dases de química. Al respecto, Molina y Farías (2005) encontraron que el uso del trabajo práctico (TP) en la secundaria es poco, 0 casi nulo (lo mismo han encontrado otros investigadores en otros continentes), lo que convierte al aprendizaje de la química en un mero saber de información, es decir se puede llegar a saber información de química, pero sin "saber hacer" química, que sería lo mismo que no saber química. La poca utilización del trabajo práctico es alarmante, hasta el punto que desalienta el aprendizaje de la química por parecer una ciencia muy abstracta (un estudiante puede aplicar el proverbio: "lo escuché y lo olvidé, lo vi y lo recordé, lo hice y lo entendí").

Pueden existir diversas razones por las que no se adelanta trabajo práctico, tales como: Falta de instalaciones, programas extensos, profesores desmotivados, falta de apoyo de directivos, etc. Sin embargo, consideramos que sobre todas las anteriores, la razón más importante es la actitud y motivación del docente. Un docente que desee innovar puede realizar un buen trabajo práctico hasta con un poco de agua de la llave y un mechero de alcohol construido con un frasco de compota. Por ello, este taller deja ejemplos que se pueden realizar con facilidad, indica a los docentes como hacerlo y propone que cada docente sea un "laboratorio ambulante"; es decir, que contemos con ideas y con la motivación necesaria para desarrollar actividades prácticas en el aula 0 laboratorio y no dependamos de las circunstancias.

\section{Trabajo Práctico (TP)}

Existen varias formas de referirse al trabajo práctico, sin embargo esta referencia es más amplia y cubre a todas las demás. Trabajo práctico o actividad práctica no es necesariamente actividad de laboratorio, pues el trabajo práctico se entiende como cualquier actividad en la cual el alumno está implicado, y no exige necesariamente estar en el laboratorio o con material o equipo especial (Hodson, 1994). Para este taller adaptaremos la clasificación de TP mostrada por Caamaño (2004) y describiremos en detalle, con aplicaciones de aula, el desarrollo de los diferentes tipos de TP (experiencias, experimentos ilustrativos, ejercicios prácticos e investigaciones).

\section{Desarrollo}

\section{Experiencias}

Dentro del aprendizaje, las experiencias son imágenes reales o representativas que sirven para obtener un acercamiento de tipo perceptivo con los fenómenos. Con éstas se puede:

$>$-Adquirir una experiencia directa de los sentidos sobre los fenómenos cient́ficos, lo que permite plantear una relación entre teoría y realidad.

> -Adquirir un conocimiento "tácito" que permanece de forma potencial para ser útil en la resolución de problemas. Por ejemplo, la imagen de una pieza mecánica y con el conocimiento que se tiene sobre ella y su utilización, puede emplearse para solucionar otro problema en un contexto diferente.

\section{Ejemplos:}

1. Polímeros y códigos de dasificación. Conocer sobre los polímeros ya no es una opción, es una necesidad, pues representan un tipo de moléculas que están presentes en muchos ámbitos de la sociedad y son daves para el desarrollo tecnológico. Estamos rodeados de plásticos y constituidos por moléculas biológicas sin las cuales no podemos vivir. Si queremos educar personas que tengan un papel importante en el desarrollo social de su región, debemos darles oportunidades y espacios para conocer acerca de los polímeros y asuntos relacionados con éstos, como son los códigos de dasificación y de reciclaje. Una experiencia sencilla, dentro de muchas posibles para este tema, consiste en llevar al aula diferentes muestras de polímeros en bolsas donde se pueda leer la información más importante de cada molécula (nombre, estructura química, propiedades, aplicaciones, etc) y con ello por ejemplo ubicar los diferentes plásticos dentro de su código de dasificación de recidaje. En esta actividad, muchos manifiestan no saber el nombre de 
determinado material que incluso han utilizado, o que "creían que todos los plásticos eran casi iguales". Además, se aprecia la textura, las diferentes representaciones comerciales para un mismo polímero (poliestireno en vasos de café), algo de sus propiedades mecánicas y se obtiene una experiencia táctil.

2 Reglas de solubilidad. El hecho que unas sustancias se solubilicen y otras no (en agua especialmente) es un fenómeno de tipo práctico que tiene explicaciones de tipo químico. Las reglas de solubilidad se dan generalmente en los textos como algo sacado de experiencias complicadas o de difíal explicación. Sin embargo, una simple experiencia con la reacción entre diferentes especies permite obtener las reglas de solubilidad de forma sencilla. Utilizamos la siguiente secuencia de reacciones en sendos tubos de ensayo:

$$
\begin{aligned}
\text { 1. } \mathrm{NiO}_{2(\mathrm{ac})}+2 \mathrm{NaOH}_{(\mathrm{ac})} \rightarrow \mathrm{Ni}(\mathrm{OH})_{2(\mathrm{~s})}+2 \mathrm{NaCl}_{(\mathrm{ac})} \\
\text { 2. } \mathrm{MgCl}_{2(\mathrm{ac})}+2 \mathrm{NaOH}_{(\mathrm{ac})} \rightarrow \mathrm{Mg}(\mathrm{OH})_{2(\mathrm{~s})}+2 \mathrm{NaC}_{(\mathrm{ac})} \\
\text { 3. } \mathrm{NiO}_{2(\mathrm{ac})}+2 \mathrm{NaNO}_{3(\mathrm{ac})} \rightarrow \mathrm{Ni}\left(\mathrm{NO}_{3}\right)_{2(\mathrm{ac})}+2 \mathrm{NaC}_{(\mathrm{ac})} \\
\text { 4. } \mathrm{NiSO}_{4(\mathrm{ac})}+2 \mathrm{NaOH}_{(\mathrm{ac})} \rightarrow \mathrm{Ni}(\mathrm{OH})_{2(\mathrm{~s})}+\mathrm{Na}_{2} \mathrm{SO}_{4(\text { (ac) }}
\end{aligned}
$$

Ante los estudiantes las reacciones se representan con letras, así:

1: $A W+B X \rightarrow$ produce un precipitado verde

2: $\mathrm{CW}+\mathrm{BX} \rightarrow$ produce un precipitado blanco

3: AW + BY $\rightarrow$ no produce precipitado.

4: $\mathbf{A Z}+\mathrm{BX} \rightarrow$ produce un precipitado verde.

Las equaciones anteriores se pueden completar, para quedar como:

$$
\begin{aligned}
& \text { 1. } A W+B X \rightarrow A X+B W \\
& \text { 2: CW + BX } \rightarrow C X+B W \\
& 3: A W+B Y \rightarrow A Y+B W \\
& \text { 4: AZ + BX } \rightarrow A X+B Z
\end{aligned}
$$

La discusión se realiza en tomo a dasificar los iones dentro de los siguientes grupos:

Cation1: siempre soluble. Cation2: forma sólidos con "aniones insolubles". Anion1: generalmente soluble. Anion2: generalmente insoluble.

Al final los estudiantes, relacionando los precipitados que se forman con las reacciones, pueden llegar a la siguiente dasificación, demostrando que de forma práctica se obtienen las reglas de solubilidad.

Cationes tipo 1: B. Cationes tipo 2: A, C. Aniones tipo 1: W, Y,Z Aniones tipo 2: X

3. Efecto de la presión. Por espacio, sólo comentamos esta experiencia. Consiste en visualizar el efecto de la presión sobre los objetos. Existen diferentes formas de hacerlo, pero una muy sencilla es calentar una lata con una pequeña cantidad de agua. Una vez posea vapor de agua dentro, la lata se tapa muy bien y se somete a un chorro de agua, con lo cual el vapor se condensa disminuyendo su presión interna, conllevando a un estrangulamiento de la lata por efecto de la presión atmosférica.

4. El proceso de digestión: efecto del jugo gástrico en la leche. En la escuela aprendemos que en el estómago existe algo llamado jugo gástrico, que entre otras cosas contiene una disolución de ácido dorhídrico; sin embargo, sobre su efecto sobre los alimentos sólo la imaginación nos puede decir algo. Con la adición de una pequeña cantidad de vinagre (ácido acético) sobre un poco de leche podemos visualizar la separación de la caseína de la leche y lo que ocurre en el estómago auando ingerimos este alimento. 
Experimentos ilustrativos

En docencia, los experimentos son utilizados para unir evidencia experimental con el aprendizaje de conceptos, o para ilustrar leyes y principios. Permiten interpretar un fenómeno, ilustrar un principio o mostrar una relación entre variables. Con su utilización se despierta la curiosidad de los estudiantes, antes y durante la elaboración del experimento, conduciendo con ánimo a los estudiantes hacia la interpretación del fenómeno mostrado. El énfasis puede colocarse más en el aspecto interpretativo que en el ilustrativo, y la aproximación puede ser cualitativa o cuantitativa. Cuando la actividad es completamente guiada por el profesor se denomina demostración. El lector puede ampliar su conocimiento sobre este tema en el trabajo titulado "Dinamizando el proceso de enseñanza-aprendizaje de la química. Las demostraciones químicas como una opción para cambiar la forma tradicional de enseñar química", presentado en este mismo congreso.

Cuando realizamos experimentos ilustrativos debemos considerar que del mismo hecho pueden surgir diferentes interpretaciones, que pueden dar lugar a un aprendizaje significativo o a un error conceptual. Por ejemplo, si realizamos una encuesta sobre el apagado de una vela dentro de un recipiente cerrado, obtendríamos un alto porcentaje que nos dice que es debido a la terminación del oxígeno. Sin embargo, esto es incorrecto. Por ello, al ejecutar demostraciones debemos tener presente las siguientes recomendaciones:

-Que los estudiantes expliquen oral o por escrito sus interpretaciones.

-El profesor debe salirle al paso a las posibles interpretaciones erróneas de los estudiantes.

-Incluir las actividades dentro de las evaluaciones corrientes.

Ejemplo:

1. La combustión de la vela Colocamos una vela dentro de un recipiente con agua y la tapamos con un vaso (figura 1). La vela se apaga rápidamente, y sobre ello plantemos los siguientes interrogantes: ¿por qué se apaga la vela? o ¿por qué sube el agua? Ante la primera pregunta los estudiantes contestan rápidamente que es por la ausencia de oxígeno. La intención es demostrar que esta no es la respuesta correcta sino que la relación oxígeno/dióxido de carbono es muy importante para mantener una combustión. Para mostrar que aún queda oxígeno en el recipiente realizamos el experimento en un montaje modificado que permite la incorporación de un ratón dentro del recipiente. El animal sigue ahí aun con la vela apagada, entonces, aún existe oxígeno (Caamaño, 2004).

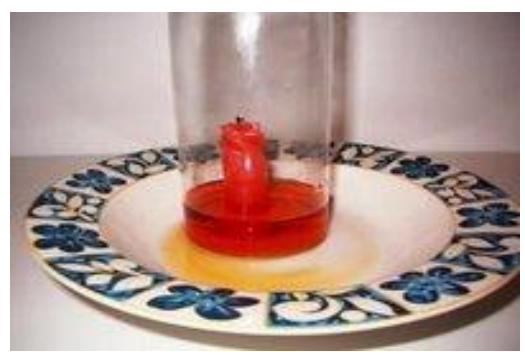

Figura 1. Montaje simple sobre la combustión de la vela.

\section{Ejercicios prácticos}

Son actividades prácticas que sirven para aprender a seguir protocolos tendientes a enseñar una destreza experimental, el uso de un equipo, un procedimiento especial de análisis o simplemente para seguir indicaciones. En ciertas actividades de la vida real basta con seguir correctamente instrucciones para llegar a un objetivo (como armar un mueble de piezas, instalar un electrodoméstico, etc), competencia que a veces obviamos por parecer simple Los ejercicios prácticos pueden ser de dos tipos: procedimentales y comoborativos. Los procedimentales presuponen un aprendizaje por etapas, desde los procedimientos más sencillos hasta los más complejos siguiendo siempre indicaciones. Los corroborativos pretenden verificar una teoría o una ley por medio de un procedimiento detallado. 


\section{Ejemplos:}

1. Calibración de un pH-metro. Tomamos el siguiente procedimiento de http: //uww.fq.uh.cu/dpto/qf/udv/techniques/phD.html.

Un pH-metro digital posee un electrodo para medir el pH de una solución.
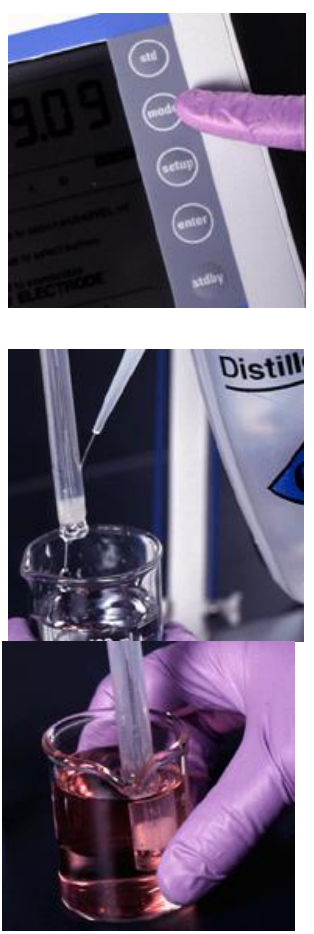

1. Presione el botón mode para seleccionar pH

2. Presione el botón Setup dos veces, luego presione el botón Enter para eliminar la estandarización existente

3. Presione el botón STD para comenzar la nueva calibración.
4. Quite el electrodo de la solución de almacenamiento. Enjuague con agua destilada.

5. Introduzca el electrodo en una solución buffer de pH conocido. Por ejemplo la de $\mathrm{pH}=\mathbf{4}$ de color rosa. Agite la solución para saturar el electrodo totalmente con el buffer.

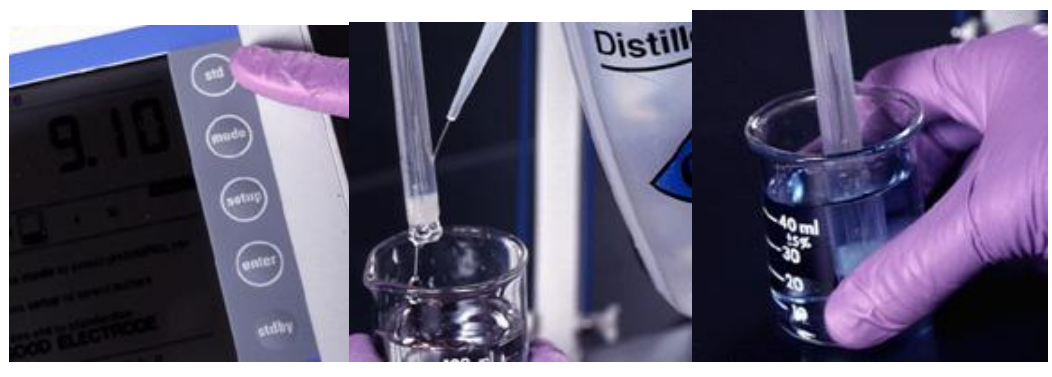

6. Presione el botón STD nuevamente. Después que la lectura sea estable, el pH-metro mostrará en la pantalla la medida del $\mathrm{pH}$. Presione el botón STD nuevamente para calibrar con una segunda solución buffer.
7. Remueva la solución del buffer de pH 4 $y$ enjuague el electrodo.
8. Introduzca el electrodo en otra solución buffer de pH conocido como la de $\mathrm{pH}=10$. Presione el botón STD nuevamente para calibrar con este buffer. El pH-metro mostrará una calibración y retomará la medida de pH a la pantalla.

Figuras 2 Proceso de calibración de un pH-metro.

Ahora que el pH-metro ha sido calibrado, puede ser usado para medir el pH de una disolución con pH desconocido. 
Aunque este procedimiento es tipo receta, el seguirlo requiere ciertas habilidades y experiencias previas (utilizar guantes, manejar un vaso, manejar un frasco lavador, trabajar con material de vidrio, interpretar funciones, interpretar la respuesta de un equipo, instalar un electrodo, etc). Es más práctico de esta manera que pretender calibrar un pHmetro mediante resolución de problemas.

2. Preparación de un indicador de repollo morado. Se pica un pedazo de repollo morado con un auchillo o picadora y se coloca en un mortero. Se macera con unos $\mathbf{2 0} \mathbf{~ m L}$ de alcohol y se lleva a un embudo con papel de filtro hasta obtener unos $10 \mathrm{~mL}$ de extracto. Se toman 14 tubos de ensayo en una gradilla y se coloca en cada uno aproximadamente $1 \mathrm{~mL}$ de las disoluciones de distinto pH que permanecen en el laboratorio. Se marca cada tubo con el pH respectivo. En cada tubo se colocan 3 gotas del extracto de repollo, se agita suavemente y se observa la coloración. Finalmente se toma una sustancia problema suministrada por el profesor y se adicionan tres gotas de indicador de repollo. Por comparación se establece el pH de la solución problema.

\section{Investigaciones}

Es una actividad que busca acercar al estudiante a la forma como se produce el conocimiento científico. Pueden enfocarse a resolver problemas teóricos o prácticos. La investigación trata de acercar al estudiante al proceso de construcción de la ciencia; es decir, seguir los pasos que utilizan los científicos para construir conocimiento. En este tipo de trabajo, el estudiante actúla como un investigador novato y el profesor como director de investigación. En otro trabajo se describe con más detalle el desarrollo de este tipo de actividad práctica (Molina y otros, 2008). Sin embargo, una investigación puede ser guiada siguiendo más o menos las siguientes fases:

1. Fase de planteamiento del problema. El profesor está encargado de buscar problemas que sean atractivos para los estudiantes (dentro de los temas enseñados), que los comprendan y que logren ubicarlos dentro del marco histórico y conceptual que ellos manejan. El problema que aquí proponemos es ¿qué cantidad de bicarbonato de sodio posee un alka-seltzer?, el aual está ubicado dentro del tema de estequiometría y gases, y es un aspecto cotidiano para el estudiante, por lo tanto suscita su interés.

2. Fase de planificación. Los estudiantes, con la dirección y sugerencias del profesor, deciden el método a utilizar, especifican el procedimiento, determinan las cantidades de reactivos a emplear y construyen un esquema guía para ir al laboratorio.

3. Fase de procedimiento. Se desarrolla en el laboratorio con la solicitud de materiales y reactivos, la construcción de los montajes y la toma de datos. Aquí se realiza el tratamiento de datos y los gráficos o cálaulos pertinentes.

4. Fase de evaluación. Comprende el análisis de los resultados, posibles modificaciones o repeticiones. Realizan comparaciones contra resultados esperados y contra otros grupos.

5. Fase de comunicación. Implica la elaboración de un informe según las características que el profesor exija (preferiblemente en la forma en que los cient́ficos comunican sus hallazgos).

6. Fase de retroalimentación. Sobre los informes se realiza una actividad de discusión de los diferentes grupos y se dan sugerencias para mejorar el trabajo. Puede suceder que algunos grupos deban repetir el procedimiento o mejorar la presentación de sus resultados.

\section{Conclusiones}

El contar con un marco conceptual para ubicar cada una de las actividades prácticas que realizamos en el aula o laboratorio nos permite caracterizar de forma sencilla cada cuestión que desarrollemos. Ese conocimiento nos ayuda a sacar un mejor provecho en la actividad de enseñar ciencias y constituye una herramienta importante en el mejoramiento de nuestra docencia. Sobre la dasificación mostrada y el taller realizado, creemos que los docentes de ciencias en Colombia pueden empezar a desarrollar proyectos que les permitan llevar a sus clases trabajos prácticos que, 
sin duda, cambiarán la forma de aprender de nuestros estudiantes, dándole mayor importancia a las actividades experimentales, que quizá constituyen la "revolución pendiente" en la enseñanza de las ciencias en escuelas y colegios de Colombiana.

\section{Bibliografía}

Caamaño, A (2004). Experiencias, experimentos ilustrativos, ejercicios prácticos e investigaciones: cuna dasificación útil de los trabajos prácticos? Alambique, 39, 8-19.

Caamaño, A. (2008). La evaluación PISA en ciencias en 2006 en España e Iberoamerica. Alambique 57, 5-11.

Hodson, D. (1994). Hacia un enfoque más cuítico del trabajo de laboratorio. Enseñanza de las ciencias, 12, 3, 229-313.

Molina, M. F y Farias, D. (2005). Conocimiento de la importancia del trabajo experimental en la enseñanza de la química en la educación secundaria. Tecne, Episteme $y$ Didaxis, Número Extraordinario, $2^{\circ}$ Congreso sobre Formación de Profesores de Ciencias, Mayo de 2005, 145.

Molina, M. F., Carriazo, J. G., Farías, D. M. (2008). Aprendiendo estequiometría a través de proyectos de investigación en el laboratorio de química general. De la teoría a la práctica en enseñanza por investigación. II Coloquio Investigación e Innovación en la Enseñanza de las Ciencias. Universidad Católica de Colombia. 28 y 30 de mayo del 2008. 